\title{
Enhancement of photosynthetic carbon assimilation efficiency by phytoplankton in the future coastal ocean
}

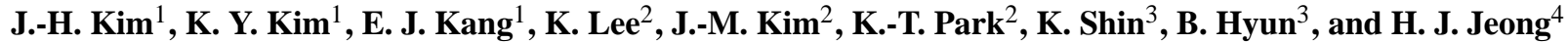 \\ ${ }^{1}$ Department of Oceanography, College of Natural Sciences, Chonnam National University, Gwangju, 500-757, South Korea \\ ${ }^{2}$ Pohang University of Science and Technology, School of Environmental Science and Engineering, \\ Pohang, 790-784, South Korea \\ ${ }^{3}$ Korea Institute of Ocean Science and Technology/South Sea Institute, Jangmok, 656-830, South Korea \\ ${ }^{4}$ School of Earth and Environmental Sciences, College of Natural Sciences, Seoul National University, Seoul, 151-747, South \\ Korea
}

Correspondence to: K. Y. Kim (kykim@chonnam.ac.kr)

Received: 20 February 2013 - Published in Biogeosciences Discuss.: 8 March 2013

Revised: 9 October 2013 - Accepted: 11 October 2013 - Published: 21 November 2013

\begin{abstract}
A mesocosm experiment was conducted to evaluate the influence of photosynthetic performance on the energetic balance of coastal phytoplankton, in relation to community production and autotrophic phytoplankton biomass in future coastal oceans. Natural phytoplankton assemblages were incubated in field mesocosms under ambient condition (control: ca. $400 \mu$ atm $\mathrm{CO}_{2}$ and ambient temperature), and two sets of potential future ocean conditions (acidification: ca. $900 \mu \mathrm{atm} \mathrm{CO}_{2}$ and ambient temperature; greenhouse: ca. $900 \mu$ atm $\mathrm{CO}_{2}$ and $3{ }^{\circ} \mathrm{C}$ warmer). The photosynthetic performances were estimated by in vivo fluorometry (effective quantum yield $\left(\Phi_{\mathrm{PSII}}\right)$, steady-state light response curves (LCs)) and in situ incorporation of ${ }^{14} \mathrm{C}$ (photosynthesisirradiance curves). The $\Phi_{\mathrm{PSII}}$ and $\mathrm{rETR}_{\mathrm{m}, \mathrm{LC}}$ (relative maximum electron transport rate) clearly reduced under acidification, in particular, when phytoplankton were exposed to high light levels. However, $\mathrm{P}_{\max }^{B}$ (maximum photosynthetic rate) was the same in the ambient and acidification conditions. Thus, phytoplankton utilized less light under acidification condition, but could still assimilate a similar amount of carbon compared to the ambient condition. The $\mathrm{P}_{\max }^{B}$ and $\alpha$ (photosynthetic efficiency) under greenhouse condition were significantly higher than those under ambient condition without any difference in $\Phi_{\mathrm{PSII}}, \mathrm{rETR}_{\mathrm{m}, \mathrm{LC}}$ and $\alpha_{\text {,LC }}$ (electron transport efficiency) between the treatments. Therefore, phytoplankton utilized the same amount of light under greenhouse condition, but could assimilate more carbon than under ambient condition. As a result, Chl $a$ normalized pri-
\end{abstract}

mary production was higher in greenhouse than in other conditions. Nevertheless, the community production did not change between the experimental treatments. The main reason for the lack of a change in primary production under future climate conditions is the control of autotrophic phytoplankton biomass by grazing. Consequently, acidification and greenhouse environments have a potential to increase growth and primary production of phytoplankton by enhancing inorganic carbon assimilation efficiency when top-down regulation is negligible.

\section{Introduction}

The ocean has been recognized as an anthropogenic $\mathrm{CO}_{2}$ reservoir since the Industrial Revolution, but ocean acidification has only recently been considered to be a critical problem. Ocean acidification involves increases in $p \mathrm{CO}_{2}$ and bicarbonate ion concentration $\left(\mathrm{HCO}_{3}^{-}\right)$and decreases in $\mathrm{pH}$ and carbonate ion concentration $\left(\mathrm{CO}_{3}^{2-}\right)$ in seawater. Changes in carbon chemistry influence phytoplankton physiology, because photosynthesis and respiration are affected by increases in $\mathrm{CO}_{2}$ and $\mathrm{HCO}_{3}^{-}$concentrations. Generally, most phytoplankton require active inorganic carbon acquisition mechanisms for photosynthesis (carbon concentrating mechanisms; $\mathrm{CCMs}$ ) to overcome $\mathrm{CO}_{2}$ limitation and their poor $\mathrm{CO}_{2}$ affinity of RuBisCO (Beardall and Raven, 2004; Raven, 2010). Thus, the photosynthesis of phytoplankton 
could be positively affected by elevated $\mathrm{CO}_{2}$ along with $\mathrm{CO}_{2}$ affinity changes and downregulation of CCMs (Rost et al., 2003; Giordano et al., 2005; Sobrino et al., 2008; Hopkinson et al., 2011). On the contrary, some phytoplankton species that have already permanently adjusted to limited $\mathrm{CO}_{2}$ environments, are not affected by oceanic $\mathrm{CO}_{2}$ increases with active CCMs (Beardall and Raven, 2004; Giordano et al., 2005). Thus, physiological changes of phytoplankton might be complicated due to the various adaptation mechanisms under high $\mathrm{CO}_{2}$ conditions, and they can heavily depend upon species-specific physiological characteristics of phytoplankton.

In response to ocean acidification, altered photosynthetic activities of different species can cause changes in cell growth and primary production, as well as in the community structure of the phytoplankton assemblage (Schippers et al., 2004; Riebesell, 2004). Some phytoplankton species have lower light-energy requirements to synthesize organic carbon under high $\mathrm{CO}_{2}$ conditions (Chen and Gao, 2004), which can be an advantage allowing more organic compounds to be produced with less light energy. Energy consumption efficiency is also optimized for cell growth and division of phytoplankton under elevated $\mathrm{CO}_{2}$ concentrations with energy savings due to the downregulation of CCMs (Sobrino et al., 2008). Previous mesocosm studies have shown that cell growth and primary production are promoted by an enhanced organic carbon assimilation rate alongside the community succession of phytoplankton (Riebesell et al., 2007). These results possibly suggest that the downregulation of CCMs could positively influence the biomass and primary production of natural phytoplankton assemblages. According to this perspective, photosynthesis, primary production and cell growth would be closely related to each other under high $\mathrm{CO}_{2}$ conditions, but there is a lack of field mesocosm observations to corroborate this.

One of many problems caused by increasing atmospheric $\mathrm{CO}_{2}$ is ocean warming. The temperature is expected to increase ca. $2-5^{\circ} \mathrm{C}$ during this century based on the IPCC A2 Scenario (IPCC, 2007), and increased temperature has a profound influence on the physiology and ecology of phytoplankton and its community structure (Feng et al., 2009; Lewandowska and Sommer, 2010; Sommer and Lewandowska, 2010). Increased temperature also accelerates photosynthesis and respiration-related metabolic processes based on $Q_{10}$ values in light-saturated productive areas (Sommer and Lengfellner, 2008). Previous studies suggest that increased temperature influences the production of phytoplankton more significantly than increased $\mathrm{CO}_{2}$ (Hare et al., 2007; Feng et al., 2009). Additionally, community structure and species composition are strongly affected by increased temperature with altered and varied biophysical activities across all trophic levels (Hare et al., 2007; Rose et al., 2009; Lewandowska and Sommer, 2010). Although increased temperature can be an important factor to regulate the physiological response of phytoplankton in future envi- ronmental conditions, pelagic mesocosm studies have rarely addressed the effects of temperature on photosynthesis and growth of the phytoplankton community, and numerous studies have focused only on the impact of elevated $\mathrm{CO}_{2}$.

In this study, we focused on physiological changes and in turn ecological responses under future climate conditions. Photosynthetic adaptation, such as downregulation of CCMs, may alter ecological parameters such as changes of biomass, primary production and species composition in future environments. All of these changes could influence the energetic balance of entire metabolic processes with a positive response of photosynthesis. Most research on the energetic balance and energy flow process in response to future environments has relied on well-controlled laboratory conditions using single phytoplankton species (Fu et al., 2007; Sobrino et al., 2008, etc.). Because in situ mesocosm data are still scarce, it is hard to decide whether or not the results from single species studies can be applied at the ecosystem level. Mesocosms help evaluate well-established hypotheses and determine organismal to ecosystem level responses to future climatic environments (Kim et al., 2008; Riebesell et al., 2008). In this study, we conducted a mesocosm experiment in the coastal waters of Korea to evaluate how future oceanic $\mathrm{CO}_{2}$ and temperature changes could affect photosynthetic activity of phytoplankton. The first aim of this study was to investigate the alteration of photosynthetic characteristics based on photosystem II chlorophyll $a$ fluorescence (i.e., PSII photochemistry) and photosynthetic radioactive carbon incorporation $\left({ }^{14} \mathrm{C}\right.$ incubation). Also, we investigate the process by which photosynthetic carbon assimilation changes under future climate conditions alter the energetic balance of plankton communities. Thus, the second aim of this study was to examine the changes in primary production and phytoplankton biomass, which strongly correlate with photosynthetic activity in future climate conditions.

\section{Materials and methods}

\subsection{Mesocosm experimental setup}

A mesocosm experiment was conducted in the southern coastal waters of Korea (Jangmok Bay, Geoje Island; $34.6^{\circ} \mathrm{N}, 128.5^{\circ} \mathrm{E}$ ), from 21 November to 11 December 2008. The mesocosm system consisted of a floating raft, $p \mathrm{CO}_{2}$ concentration regulation units, seawater-mixing units, and mesocosm enclosures (Kim et al., 2008). The mesocosm facility consisted of nine polyethylene gas-tight enclosures. Three sets of experimental conditions were simulated in the initial phase of the experiment based on IPCC A2 Scenarios (IPCC, 2007): (1) ambient (control: ca. $400 \mu \mathrm{atm} \mathrm{CO}_{2}$ and ambient temperature), (2) $\mathrm{CO}_{2}$ only enriched (acidification: ca. $900 \mu \mathrm{atm} \mathrm{CO}_{2}$ and ambient temperature), and (3) both increased $\mathrm{CO}_{2}$ and temperature (greenhouse: ca. $900 \mu$ atm $\mathrm{CO}_{2}$ and $3{ }^{\circ} \mathrm{C}$ warmer than ambient temperature) 
(Fig. S-1A). About 1.6 tons of natural seawater was transferred into each mesocosm enclosure, and the initial $\mathrm{Chl} a$ concentration of seawater was ca. $1 \mu \mathrm{g} \mathrm{L}^{-1} . \mathrm{CO}_{2}$-saturated seawater was slowly diluted with natural seawater using a peristaltic pump to initiate the high $\mathrm{CO}_{2}$ condition at the beginning of the experiment. The target concentration of $\mathrm{CO}_{2}$ flowed into the headspace of the mesocosm bags for the entire duration of the experiment. A small fraction (ca. $0.5 \mathrm{~L} \mathrm{~min}^{-1}$ ) of $\mathrm{CO}_{2}$ also flowed into the seawater through the mixing unit for $20 \mathrm{~min}$ just before the daily seawater sampling. The bubbling time was sufficient to mix all the suspended and deposited material without causing bubbling effects on the living cells (Kim et al., 2008). This $\mathrm{CO}_{2}$ gas regulation during the experimental period is not enough to maintain the initial conditions of $p \mathrm{CO}_{2}$ because seawater carbon chemistry is very sensitive to biological activity. The $\mathrm{CO}_{2}$ concentration was allowed to fluctuate due to biological activity during the experiment. The experiments were designed to interpret physiological responses of phytoplankton to future conditions, but not to specific $\mathrm{CO}_{2}$ and temperature levels. To maintain the high temperature in the greenhouse condition, a heat exchange tube (PEX-A-PEX, Type$\left.1216\left(1 / 2^{\prime \prime}\right)\right)$ was wrapped around the seawater-mixing unit at a water depth of $1.5-2.0 \mathrm{~m}$. The heated freshwater circulated through the tubing with a flow rate of $25 \mathrm{~L} \mathrm{~min}^{-1}$; this was generated by a heating bath circulator (maximum heating capacity: $1 \mathrm{~kW}$ ). This setup was enough to create seawater treatments $2-3{ }^{\circ} \mathrm{C}$ warmer than the ambient temperature regardless of natural temperature fluctuations during the whole experimental period (Fig. S-1C). Nutrients were added to each enclosure to create a phytoplankton bloom at the initial phase of the experiment (nitrate + nitrite: ca. $41 \mu \mathrm{mol} \mathrm{kg}{ }^{-1}$, phosphate: ca. $2.5 \mu \mathrm{mol} \mathrm{kg}{ }^{-1}$, and silicate: ca. $50 \mu \mathrm{mol} \mathrm{kg}{ }^{-1}$; see Fig. S-2). Approximately $10 \mathrm{~L}$ of seawater was collected for daily sampling, and more than 1.3 tons of seawater remained in the mesocosm enclosures on the final day of the experiment. Further details of the experimental conditions, including the $\mathrm{CO}_{2}$ concentration and $\mathrm{pH}$, are provided in the Supplement, and in companion papers (Kim et al., 2010, 2011b).

\subsection{Autotrophic phytoplankton biomass $(\mathrm{Chl} a)$}

The biomass ( $\mathrm{Chl} a$ ) of autotrophic phytoplankton was determined fluorometrically using a Turner 10-AU fluorometer (Turner Designs Inc., Sunnyvale, CA, USA) by filtering known volumes of seawater through GF/F filters (Whatman, Maidstone, UK). Chl $a$ was extracted with $90 \%$ acetone for $24 \mathrm{~h}$ in the dark (Holm-Hansen and Riemann, 1978).

\subsection{Chl $a$ fluorescence}

Seawater samples were collected 7-8 times during the day (06:00-19:00 local standard time-KST) under various irradiance conditions $\left(0-1200 \mu \mathrm{mol}\right.$ photons $\left.\mathrm{m}^{-2} \mathrm{~s}^{-1}\right)$. The ef- fective quantum yield of PSII ( $\Phi_{\text {PSII }}$ ) was measured using an in vivo Chl $a$ fluorometer (Phyto-PAM, Heinz Walz, Effeltrich, Germany). Measuring light pulses were generated by an array of light-emitting diodes (LED) with 4 different wavelengths, and a blue $(470 \mathrm{~nm})$ wavelength which was chosen to induce excitation of antenna pigments of autotrophic phytoplankton (Kim et al., 2013). $\Phi_{\text {PSII was ob- }}$ tained using a saturation pulse after exposure to different intensities of actinic light (light intensities were determined by in situ irradiance at sampling time), and was calculated as $\Phi_{\mathrm{PSII}}=\Delta F / F_{\mathrm{m}}{ }^{\prime}=\left(F_{\mathrm{m}}{ }^{\prime}-F\right) / F_{\mathrm{m}}{ }^{\prime}$, where $F$ and $F_{\mathrm{m}}{ }^{\prime}$ represent the steady-state fluorescence and maximum fluorescence measured in the light, respectively. These results represent the apparent efficiency of open PSII reaction centers at each sampled time, after complete photoacclimation to ambient light intensities. The relative electron transfer rate (rETR) was calculated as rETR $=\Phi_{\text {PSII }} \times$ irradiance. The absorption factor and relative fraction of PSII were not applied to the ETR calculation. Steady-state light response curves (LCs) were constructed as rETR-I curves, which were fitted to a model with the photoinhibition parameter of Platt et al. (1980) to distinguish the efficiency of the PSII reaction centers as they would related to future environmental conditions. The photosynthetic parameters of $\mathrm{Chl} a$ fluorescence derived from LC fitting represented as the maximum relative electron transport rate $\left(\mathrm{rETR}_{\mathrm{m}, \mathrm{LC}}\right.$ : maximum $\mathrm{rETR}$ capacity), electron transport efficiency ( $\alpha$, LC: efficiency quanta used in PSII electron transport), and the light saturation intensity of the LCs $\left(E_{\mathrm{k}, \mathrm{LC}}\right.$ : light level reaches saturation for rETR). All fluorescence measurements were carried out on days $1,5,9,15$, and 19 from all mesocosm enclosures.

\subsection{Gross photosynthesis}

Seawater samples were collected at 10:00 LT for gross photosynthesis measurements derived from ${ }^{14} \mathrm{C}$ incorporation. An $80 \mathrm{~mL}$ aliquot of seawater from each mesocosm enclosure was placed in a cell culture flask (Corning Inc., NY, USA), and $0.5 \mu \mathrm{Ci}$ of $\mathrm{NaH}^{14} \mathrm{CO}_{3}$ was inoculated to initiate the incubation experiment. The incubation bottles were wrapped with dark and neutral density screens with eight different light transmissions to provide various intensities of light $(0,6,13,17,30,43,67$, and $100 \%)$ in the middle of the day. After $3 \mathrm{~h}$ of incubation, the seawater was filtered through a glass membrane filter $(\mathrm{GF} / \mathrm{F})$, and the filter paper was placed in a $20 \mathrm{~mL}$ plastic scintillation vial (PerkinElmer, Waltham, MA, USA). Acid fuming with $1 \mathrm{~mL}$ of $0.5 \mathrm{~N} \mathrm{HCl}$ was undertaken for 1 day under dark conditions, and then $10 \mathrm{~mL}$ of UltimaGold ${ }^{\mathrm{TM}}$ (PerkinElmer) scintillation cocktail was added to the scintillation vial. The radioactivity of synthesized particulate carbon was measured with a liquid scintillation counter (Tri-Carb 2100 TR, Packard Instruments Co., Downers Grove, IL, USA), and the carbon uptake was calculated using an equation derived by Strickland and Parsons (1972). The results are shown as 
photosynthesis-irradiance (P-I) curves, and fitted to a model with the photoinhibition parameter of Platt et al. (1980). Photosynthetic parameters such as the $\mathrm{Chl} a$ specific maximum photosynthetic ${ }^{14} \mathrm{C}$ assimilation rate $\left(\mathrm{P}_{\max }^{B}\right)$, photosynthetic ${ }^{14} \mathrm{C}$ assimilation efficiency $(\alpha)$, and irradiance at the onset of light saturation $\left(E_{\mathrm{k}}\right)$ were obtained from the curve fitting. P-I curves were obtained on days $0,4,8,12,16$, and 21 from all mesocosm enclosures.

\subsection{Gross community production (GCP)}

Primary production was calculated using ${ }^{14} \mathrm{C}$ uptake photosynthetic parameters and $\mathrm{Chl} a$ concentration with the time series of incident light data. This is considered to represent water column light attenuation, and data were expressed as gross community production (GCP). In situ daily irradiance was measured using a LI-1400 data logger with a LI-COR $2 \pi$ PAR sensor (LI-190 and LI-192, LI-COR Inc., Lincoln, NE, USA). The quantum sensors were positioned in the atmosphere and at $1 \mathrm{~m}$ water depth outside the mesocosm enclosures; and five HOBO Pendant Temperature/Light data loggers (Onset Computer Corp., Bourne, MA, USA) were installed randomly at a $1 \mathrm{~m}$ water depth inside and outside enclosures to examine the internal light intensity. GCP was expressed as volume-based, cumulative, and Chl $a$ normalized GCP.

\subsection{Statistical analysis}

Analysis of variance (ANOVA) was used to identify the statistical difference between the treatments (ambient, acidification and greenhouse conditions), including P-I curves and LCs parameters. All datasets met the assumptions of normality and homogeneity of variance. When the ANOVA identified a significant difference $(p<0.05)$, Tukey's HSD post hoc comparison was used. These analyses were performed using SPSS 17.0 (SPSS Inc., Chicago, IL, USA).

\section{Results}

\subsection{Autotrophic phytoplankton biomass ( $\mathrm{Chl} a)$}

The mesocosm experiment was divided into three periods in terms of autotrophic phytoplankton biomass and nutrient levels (pre-bloom period: days 0-5; bloom period: days 614; and post-bloom period: days 15-21) (Fig. 1). The phytoplankton biomass increased slowly during the pre-bloom period with no differences between the experimental conditions, and it reached about $5 \mu \mathrm{g} \mathrm{Chl} a \mathrm{~L}^{-1}$ monotonously at the end of this period. When the biomass increased exponentially, it leads to slightly higher Chl $a$ under the acidification condition than under the ambient condition until day 13. However, the highest phytoplankton biomass reached $35 \mu \mathrm{g} \mathrm{Chl} a \mathrm{~L}^{-1}$ under the ambient condition at the end of the exponential growth period (day 14). Subsequently, inorganic

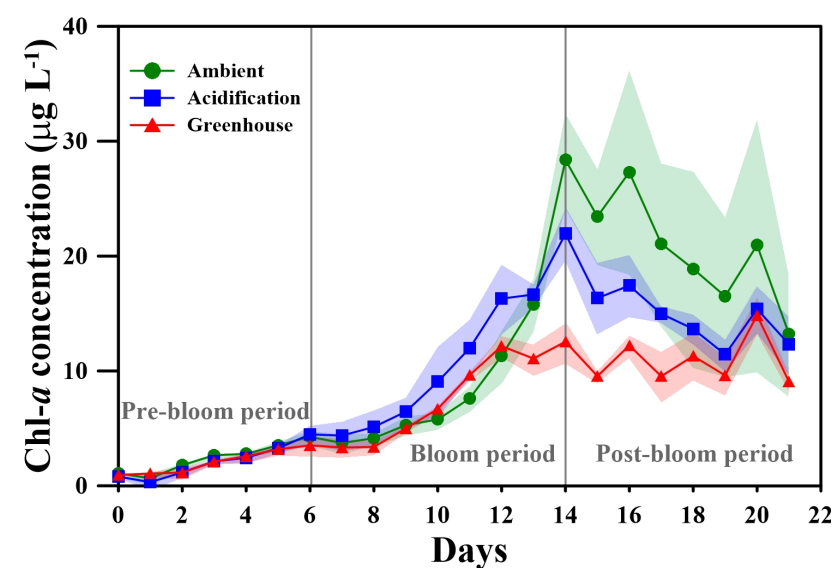

Fig. 1. Autotrophic phytoplankton biomass ( $\mathrm{Chl} a$ concentration) during the experimental period under the ambient (green), acidification (blue), and greenhouse (red) treatment conditions. Colored shading represents the standard deviation from the mean (colored symbols and lines) of the replicate enclosures $(n=3)$.

nutrients (nitrate + nitrite and phosphate) were depleted in all mesocosms (Fig. S2a, b), and the biomass also declined. This characterized a post-bloom period under the ambient and acidification conditions. In contrast, after 12 day incubation under greenhouse conditions, the autotrophic phytoplankton biomass (maximum $=14.8 \mu \mathrm{g} \mathrm{Chl} a \mathrm{~L}^{-1}$ ) did not increased remarkably (Fig. 1).

\subsection{Chl $a$ fluorescence parameters}

The effective quantum yield ( $\left.\Phi_{\text {PSII }}\right)$ showed a typical diurnal pattern that was intimately linked to the daily irradiance fluctuation (Fig. 2, left column). The $\Phi_{\text {PSII }}$ was $0.6-0.7$ under low irradiances (at dawn and dusk) and decreased with increasing light intensity. The $\Phi_{\text {PSII }}$ was extremely low at 12:00 LT when the phytoplankton was exposed to high light intensity $\left(780-1188 \mu \mathrm{mol}\right.$ photons $\mathrm{m}^{-2} \mathrm{~s}^{-1}$ ), ranging from 0.0 to 0.2 for the overall experimental period. The general trend of $\Phi_{\text {PSII }}$ was slightly reduced in the acidification condition compared to the ambient and greenhouse conditions, but it is difficult to distinguish between the experimental conditions. Such trivial differences in $\Phi_{\text {PSII }}$ could lead to significant differences of rETR when phytoplankton is exposed to high light because total utilizable photon density is extremely high. Again, differences of $\Phi_{\mathrm{PSII}}$ are more clearly distinguished in the rETR-I curves (LCs; steady-state light response curves), especially in the photoinhibition region. The pattern of LCs was not affected by experimental conditions on the first day of the experiment. After day 5 , rETR decreased in high light levels (photoinhibition region) under the acidification rather than the ambient and greenhouse conditions (Fig. 2, right column). Among the LC parameters, $\mathrm{rETR}_{\mathrm{m}, \mathrm{LC}}$ had no statistical difference between the experimental conditions during the pre-bloom period 

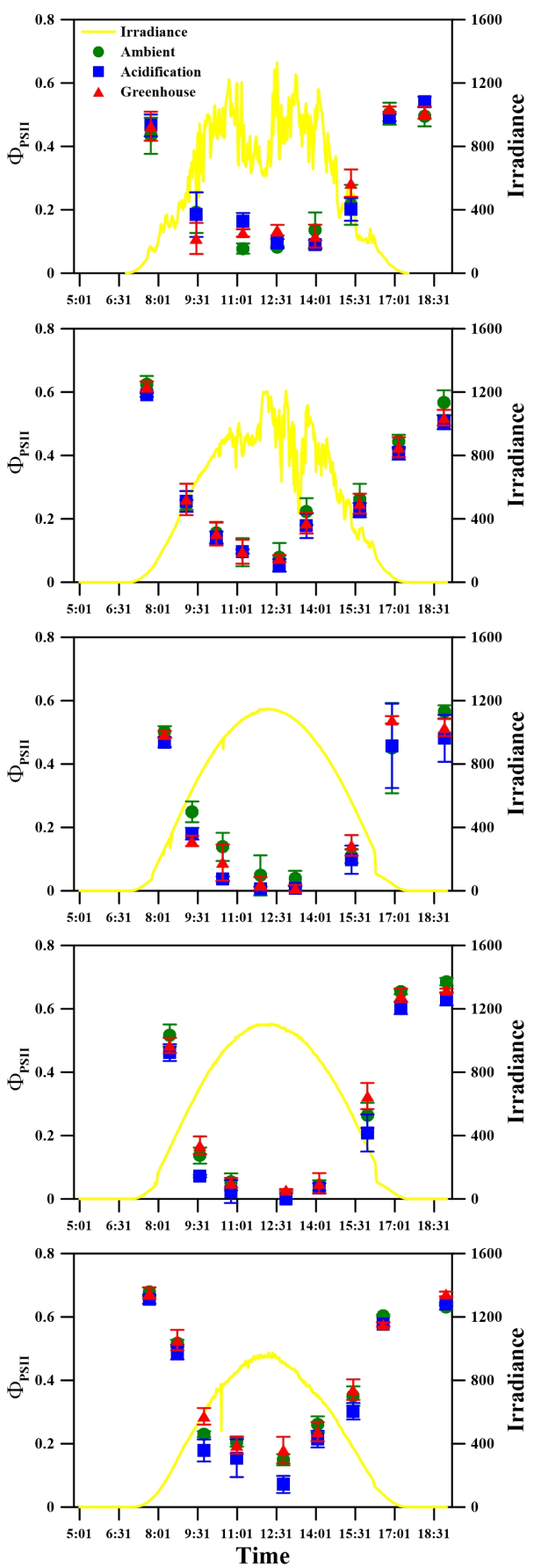
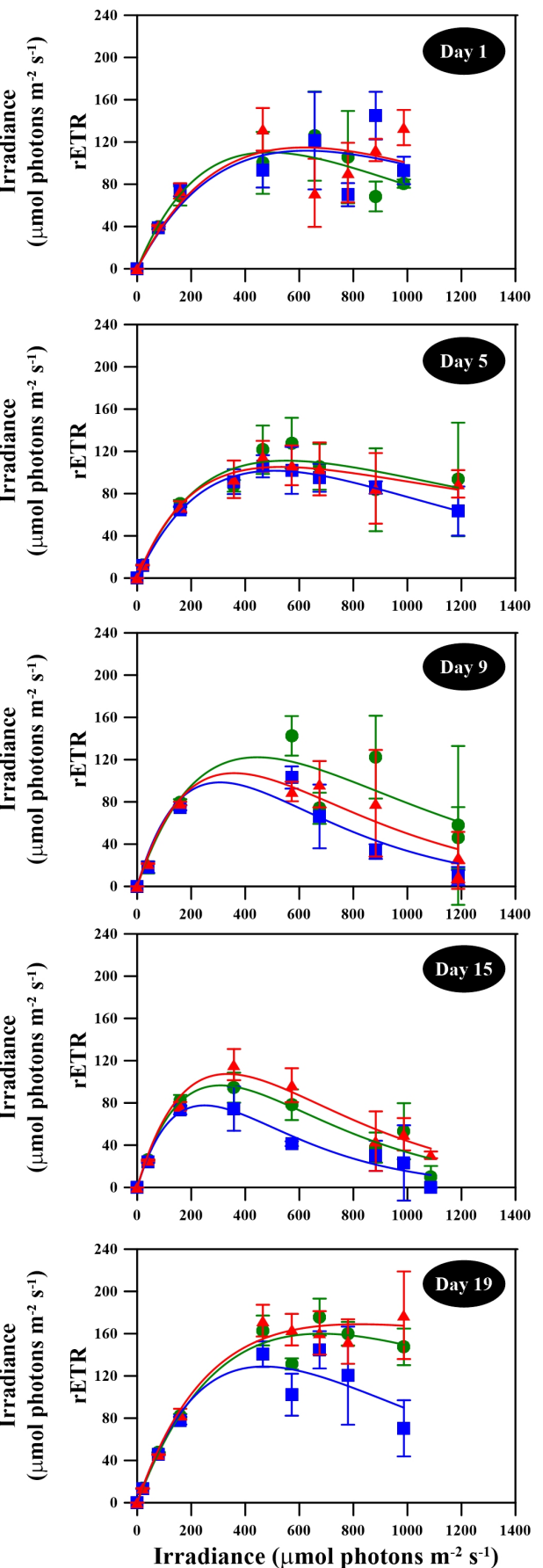

Fig. 2. Effective quantum yield of PSII ( $\Phi_{\text {PSII }}$, left column), and steady-state light response curves (rETR-I curves (LCs), right column) of the phytoplankton community during the experimental period under the ambient (green), acidification (blue), and greenhouse (red) treatment conditions. Error bars represent the standard deviation from the mean of replicate enclosures $(n=3)$.

(Table 1). Otherwise, $\mathrm{rETR}_{\mathrm{m}, \mathrm{LC}}$ values under the acidification condition were statistically lower compared to those in the other conditions on days 9 and 15, and these values were reduced compared to those of the ambient condition on day 9 and the greenhouse condition on day $15(p<0.05)$. The highest $\mathrm{rETR}_{\mathrm{m}, \mathrm{LC}}$ was observed on day 19 during the post-bloom period (130.5-167.1). Other parameters $\left(\alpha_{\text {,LC }}\right.$ and $\left.E_{\mathrm{k}, \mathrm{LC}}\right)$ showed no statistical difference between experimental conditions over the experimental period, except for $\alpha_{\text {,LC }}$ on day 1 . The highest $\alpha$, LC occurred on day 15 when Chl $a$ reached a peak in the ambient and acidification conditions (0.86-0.95). Nevertheless, relatively small changes in 
Table 1. Photosynthetic parameters from steady-state light response curves (LCs) of phytoplankton community during the experimental period. Different letters indicate a significant difference based on Tukey's multiple comparison $(p<0.05)$.

\begin{tabular}{|c|c|c|c|c|c|c|c|c|c|}
\hline \multirow[b]{2}{*}{ Day } & \multicolumn{3}{|c|}{$\begin{array}{c}\qquad \mathrm{rETR}_{\mathrm{m}, \mathrm{LC}} \\
\text { Maximum relative electron transport rate } \\
\text { (a.u.) }\end{array}$} & \multicolumn{3}{|c|}{$\begin{array}{c}\alpha_{, \mathrm{LC}} \\
\text { Electron transport efficiency } \\
\text { (a.u.) }\end{array}$} & \multicolumn{3}{|c|}{$\begin{array}{c}E_{\mathrm{k}, \mathrm{LC}} \\
\text { Light-saturation coefficient of LCs } \\
\left(\mu \mathrm{mol} \text { photons } \mathrm{m}^{-2} \mathrm{~s}^{-1}\right)\end{array}$} \\
\hline & Ambient & Acidification & Greenhouse & Ambient & Acidification & Greenhouse & Ambient & Acidification & Greenhouse \\
\hline Day 1 & $118.3 \pm 38.8$ & $104.6 \pm 14.3$ & $110.8 \pm 20.7$ & $0.54 \pm 0.08^{\mathrm{a}}$ & $0.64 \pm 0.06^{\mathrm{ab}}$ & $0.74 \pm 0.01^{\mathrm{b}}$ & $218.2 \pm 67.4$ & $163.4 \pm 15.8$ & $149.3 \pm 26.7$ \\
\hline Day 5 & $120.2 \pm 6.6$ & $101.8 \pm 7.6$ & $116.5 \pm 19.6$ & $0.54 \pm 0.15$ & $0.55 \pm 0.01$ & $0.56 \pm 0.18$ & $237.7 \pm 75.6$ & $185.5 \pm 16.7$ & $230.4 \pm 120.1$ \\
\hline Day 9 & $133.2 \pm 27.6^{\mathrm{a}}$ & $97.8 \pm 11.3^{\mathrm{ab}}$ & $107.5 \pm 3.7^{\mathrm{ab}}$ & $0.69 \pm 0.20$ & $0.80 \pm 0.04$ & $0.63 \pm 0.24$ & $215.1 \pm 118.6$ & $121.8 \pm 9.1$ & $195.8 \pm 100.7$ \\
\hline Day 15 & $96.3 \pm 6.1^{\mathrm{ab}}$ & $77.5 \pm 12.6^{\mathrm{a}}$ & $107.9 \pm 12.8^{b}$ & $0.86 \pm 0.09$ & $0.95 \pm 0.03$ & $0.88 \pm 0.07$ & $112.1 \pm 5.7$ & $79.4 \pm 15.1$ & $124.1 \pm 21.8$ \\
\hline Day 19 & $162.3 \pm 14.8$ & $131.5 \pm 15.1$ & $167.1 \pm 16.9$ & $0.67 \pm 0.05$ & $0.66 \pm 0.04$ & $0.72 \pm 0.03$ & $224.3 \pm 32.8$ & $200.6 \pm 25.1$ & $231.9 \pm 17.9$ \\
\hline
\end{tabular}

LC parameters occurred in the experimental conditions, and overall, $\mathrm{rETR}_{\mathrm{m}, \mathrm{LC}}$ and $E_{\mathrm{k}, \mathrm{LC}}$ in the acidification condition were clearly lower than in the other conditions except on day 1.

\subsection{Photosynthetic ${ }^{14} \mathrm{C}$ assimilation parameters}

On the initial day of the experiment, the photosynthetic performance of the phytoplankton community showed no statistical difference between the ambient and future climate conditions (Fig. 3; Table 2). The $\mathrm{P}_{\max }^{B}$ in the bloom period (days 8 and 12) was higher than that of the pre-bloom (ca. 30\%) and post-bloom (ca. 50\%) periods. This parameter showed a significantly lower value under the acidification condition on day $4(p<0.05)$, but there was no statistical difference in $\mathrm{P}_{\max }^{B}$ between the ambient and acidification conditions after day $4(p>0.05)$. During the post-bloom period, $\mathrm{P}_{\max }^{B}$ was significantly higher under the greenhouse condition than under the ambient condition on day $16(p<0.05)$ and under the acidification condition on days 16 and $21(p<0.05)$. No significant difference was found in $\alpha$ between the experimental conditions during the pre-bloom and bloom periods (Table 2). Statistically higher $\alpha$ values were found under the greenhouse condition compared to the acidification condition during the post-bloom period ( $p<0.05$ ). The $E_{\mathrm{k}}$ ranged from 96-189 $\mu$ mol photons $\mathrm{m}^{-2} \mathrm{~s}^{-1}$ during the entire experimental period, but no significant differences were found between the ambient and future climate treatments for $E_{\mathrm{k}}$, except on day $4(p>0.05)$.

\subsection{Gross community production (GCP)}

The gross community production (GCP) of autotrophic phytoplankton initially ranged from 4.9 to $8.0 \mu \mathrm{mol} \mathrm{CL}^{-1} \mathrm{~d}^{-1}$, and then increased slowly to $22.0 \mu \mathrm{mol} \mathrm{CL} \mathrm{C}^{-1} \mathrm{~d}^{-1}$ during the pre-bloom period, showing no differences between experimental conditions (Fig. 4a). During the bloom period, GCP increased rapidly in all conditions to values around 5 times higher than those on day 5 , and reached a peak on day 14 when the highest $\mathrm{Chl} a$ occurred. The highest value

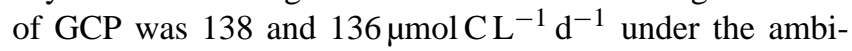
ent and acidification conditions, respectively. The GCP de- creased after the peak value to ca. $54 \mu \mathrm{mol} \mathrm{CL} \mathrm{L}^{-1} \mathrm{~d}^{-1}$ during the post-bloom period. The cumulative GCP increased exponentially until day 14 (mean value: $599.0 \mu \mathrm{mol} \mathrm{CL}^{-1}$; during the pre-bloom and bloom periods), and then increased linearly (Fig. 4b). The total cumulative GCP was higher under the ambient $\left(1069.5 \pm 322.7 \mu \mathrm{mol} \mathrm{CL}^{-1}\right)$ than under the acidification and greenhouse conditions $(991.3 \pm 64.2$ and $958.8 \pm 32.5 \mu \mathrm{mol} \mathrm{CL^{-1 }}$, respectively), but remarkable differences were not observed between the experimental conditions. Although the daily and cumulative GCPs were not extensively affected by future climate conditions, the $\mathrm{Chl} a$ normalized GCP was more enhanced under greenhouse than under ambient and acidification conditions (Fig. 4c). Overall, the Chl $a$ normalized GCP ranged from 1.6 to $10.6 \mu \mathrm{molC}_{\mu \mathrm{g}}^{-1} \mathrm{Chl} a \mathrm{~d}^{-1}$ during the mesocosm experimental period, and it varied with the daily light intensity. The Chl $a$ normalized GCP of the greenhouse treatment were higher than in the ambient and acidification conditions, especially during the blooming (days 7-10) and post-bloom periods (after day 14).

\section{Discussion}

\subsection{Physiological implications}

This mesocosm experiments elucidated the photophysiological aspects based on actual responses of the PSII photochemistry. Also, the responses of photosynthesis of phytoplankton differed regarding the timing of blooms and community structure in future coastal ocean conditions. As far as we know, this is the first pelagic mesocosm study to evaluate the effects of future oceanic conditions on the physiological changes of phytoplankton through PAM (pulse-amplitude modulation) measurements. One previous field microcosm study focused on photo-physiological responses with a PAM fluorometer to evaluate the physiological effects of elevated $\mathrm{CO}_{2}$ on a phytoplankton community (Gao et al., 2012). Our study first explored the energy balance changes from photosynthetic carbon assimilation to primary production and growth unlike previous studies. 

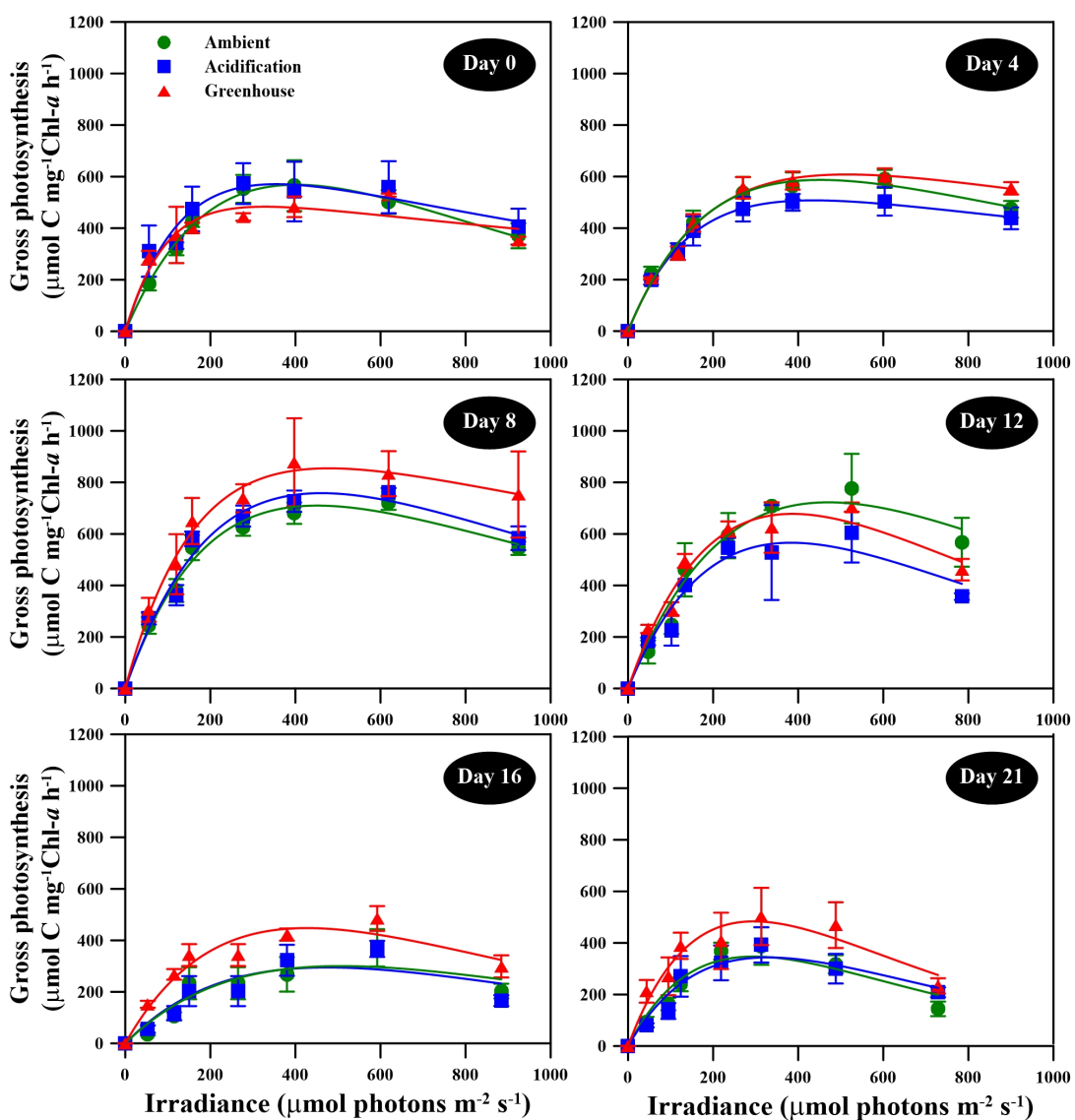

Fig. 3. Photosynthesis-irradiance (P-I) curves obtained by in situ incorporation of ${ }^{14} \mathrm{C}$ during the experimental period in the ambient (green), acidification (blue), and greenhouse (red) treatment conditions. Error bars represent the standard deviation from the mean of replicate determinations $(n=3)$.

Table 2. Photosynthetic parameters from photosynthesis-irradiance $(\mathrm{P}-\mathrm{I})$ curves of the phytoplankton community obtained by the ${ }^{14} \mathrm{C}$ uptake experiment. Different letters indicate a significant difference based on Tukey's multiple comparison $(p<0.05)$.

\begin{tabular}{|c|c|c|c|c|c|c|c|c|c|}
\hline \multirow[b]{2}{*}{ Day } & \multicolumn{3}{|c|}{ 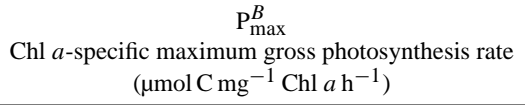 } & \multicolumn{3}{|c|}{ 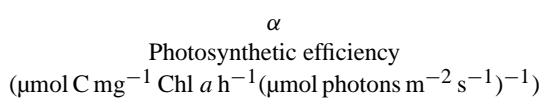 } & \multicolumn{3}{|c|}{$\begin{array}{l}E_{\mathrm{k}} \\
\text { Irradiance at the onset of light saturation } \\
\left(\mu \mathrm{mol} \text { photons } \mathrm{m}^{-2} \mathrm{~s}^{-1}\right)\end{array}$} \\
\hline & Ambient & Acidification & Greenhouse & Ambient & Acidification & Greenhouse & Ambient & Acidification & Greenhouse \\
\hline Day 0 & $18+483$ & $0.6 \pm 98.8$ & & & $5.38 \pm 0.89$ & & $149.0 \pm 7.9$ & $106.1 \pm 7.7$ & \\
\hline Day 4 & $603.8 \pm 34.4^{\mathrm{a}}$ & $508.2 \pm 42.3^{b}$ & $630.0 \pm 21.9^{\mathrm{a}}$ & $3.70=$ & $4.12 \pm 0.53$ & & $164.3 \pm 15.6^{\mathrm{a}}$ & $123.9 \pm 7.5^{\mathrm{ab}}$ & \\
\hline Day 8 & $731.4 \pm 29.6$ & $767.4 \pm 35.2$ & $876.8 \pm 111.1$ & $4.31 \pm 0.35$ & $4.66 \pm 0.43$ & & $170.2 \pm 7.4$ & $165.4 \pm 13.5$ & \\
\hline Day 12 & $730.8 \pm 108.4$ & $566.1 \pm 91.6$ & $678.1 \pm 46.3$ & $4.25 \pm 0.61$ & $4.29 \pm 0.25$ & $4.77 \pm 0.36$ & $171.8 \pm 3.2$ & $129.9 \pm 21.8$ & $142.2 \pm 5.3$ \\
\hline Day 16 & $301.1 \pm 60.1^{\mathrm{a}}$ & $296.4 \pm 30.7^{\mathrm{a}}$ & $445.5 \pm 34.8^{b}$ & $1.61 \pm 0.44^{\mathrm{a}}$ & $1.70 \pm 0.36^{\mathrm{a}}$ & $2.96 \pm 0.44^{\mathrm{b}}$ & $189.0 \pm 20.1$ & $177.6 \pm 26.2$ & $151.6 \pm 12.9$ \\
\hline Day 21 & $347.4 \pm 32.0^{\mathrm{ab}}$ & $345.2 \pm 56.8^{\mathrm{a}}$ & $478.0 \pm 98.1^{\mathrm{b}}$ & $3.19 \pm 0.41^{\mathrm{ab}}$ & $2.85 \pm 0.80^{\mathrm{a}}$ & $4.68 \pm 0.78^{b}$ & $109.3 \pm 5.9$ & $124.4 \pm 18.5$ & $102.3 \pm 14.6$ \\
\hline
\end{tabular}

The key physiological finding of this study is that phytoplankton could assimilate inorganic carbon for photosynthesis more efficiently under acidification and greenhouse conditions compared to the ambient condition. This can be interpreted from the effective quantum yield ( $\left.\Phi_{\text {PSII }}\right)$ and steady-state response curves (LCs) (Fig. 2), the P-I curves (Fig. 3), and their photosynthetic parameters (Tables 1, 2). The primary evidences for this interpretation are (1) the lower $\Phi_{\text {PSII }}$ and $\mathrm{rETR}_{\mathrm{m}, \mathrm{LC}}$ under the acidification condition compared to the ambient condition without a decrease in ${ }^{14} \mathrm{C}$ inorganic carbon incorporation, and (2) enhanced photosynthetic activity (e.g., increased $\mathrm{P}_{\max }^{B}$ and $\alpha$ ) under the greenhouse condition compared to the ambient condition without changes in the $\Phi_{\text {PSII }}$ and LC parameters. Phytoplankton utilize less light energy under the acidification condition but could assimilate a similar amount of carbon as in the ambient condition (from the 1st evidence). Also, they utilize the same light energy under the greenhouse condition, but 

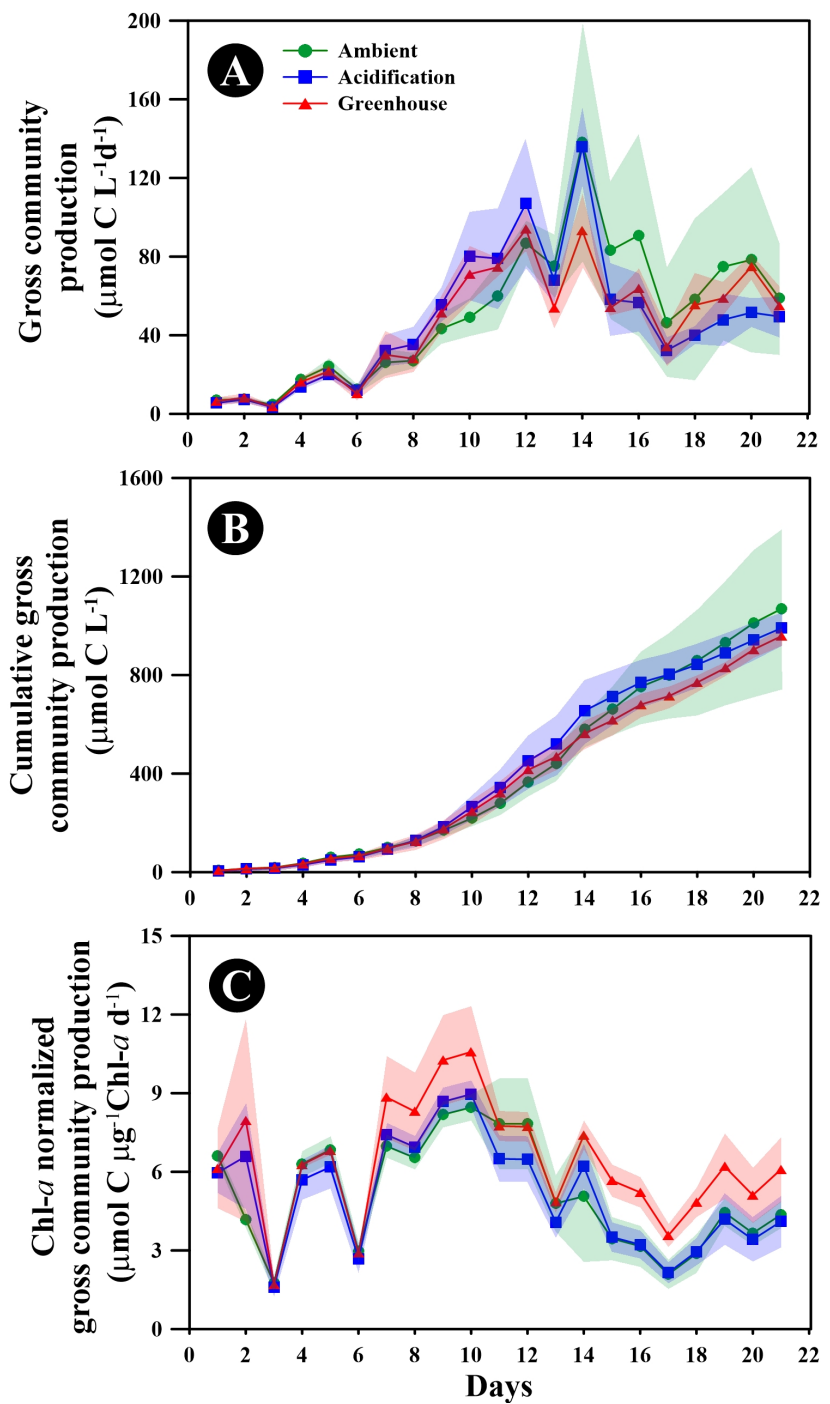

Fig. 4. Gross community production (GCP) (A), cumulative GCP (B), and Chl $a$ normalized GCP (C) based on photosynthetic parameters, in situ irradiance profiles, and $\mathrm{Chl} a$ concentration during the experimental period in the ambient (green), acidification (blue), and greenhouse (red) treatment conditions. Colored shading represents the standard deviation from the mean (colored symbols and lines) of replicate enclosures $(n=3)$.

could assimilate more carbon than in the ambient condition (from the 2nd evidence). In this study, we avoid direct comparisons between LCs and P-I curves because several significant factors affect PSII photoinactivation and photochemistry (McCarthy et al., 2012). In particular, comparisons between LCs and P-I curves are not meaningful because the functional absorption section of PSII ( $\left.\sigma_{\text {PSII }}\right)$ and the absorption factor are not considered in this study. Although $\sigma_{\mathrm{PSII}}$ is affected by environmental conditions such as $\mathrm{CO}_{2}$, temperature, irradiance, and community structure (MacKenzie et al., 2004, 2005), the LCs are an optimized tool to distinguish differences of $\Phi_{\text {PSII }}$ because it clearly reflects small changes of $\Phi_{\text {PSII }}$ under different light conditions (Kim et al., 2011a). From the pattern of the LCs, rETR was obviously downregulated within a photoinhibition region under the acidification condition, also this tendency indirectly suggested that $\Phi_{\text {PSII }}$ was reduced significantly. However, the photoinhibition parameter from the LCs $(\beta)$ did not show any statistical differences between treatments because the irradiance range of the region of photoinhibition was too narrow to estimate the photoinhibition parameter (Fig. S-5D). Consequently, the phytoplankton benefited the most from the acidification and greenhouse conditions with respect to light utilization efficiency for synthesizing organic products.

Previous laboratory studies showed similar results to our mesocosm experiment in respect of the energetic advantage of photosynthesis (Sobrino et al., 2008; Wu et al., 2010). It was hypothesized that the surplus energy obtained from the downregulation of CCMs could be used for cell growth with improved photosynthetic activity. The downregulation of CCMs is indirectly linked to light requirements and carbon assimilation processes. Only $50 \%$ of the photosynthetic energy is generally allocated to growth, and $20 \%$ of the energy is consumed by the active pathway of carbon uptake with CCMs operation (Raven, 1991; Riebesell, 2004). However, less light energy is required for operating CCMs under high $\mathrm{CO}_{2}$ conditions with depression of carbonic anhydrase activity (Hopkinson et al., 2010). The surplus energy saved from lower operation of the CCMs could activate the downregulation of a light-harvesting system due to the low light energy requirements. Thus, the phytoplankton takes advantage of photosynthesis and cell growth with efficient light energy utilization.

The greenhouse condition positively influences photosynthetic activity during the post-bloom period in this study. Carbon assimilation parameters were further increased (especially $\mathrm{P}_{\max }^{B}$ and $\alpha$ ) under the greenhouse condition with no change in PSII photochemical properties (Fig. 2; Table 1). The photosynthetic performance is accelerated by an optimized temperature condition (Claquin et al., 2008). The greenhouse condition showed a temperature range from 14.1 to $16.5^{\circ} \mathrm{C}$ during the experimental period, and temperature under ambient and acidification conditions were ca. $2-3{ }^{\circ} \mathrm{C}$ colder than greenhouse conditions (Fig. S-1C). The temperature range for the greenhouse conditions is closer to optimal conditions for photosynthesis than ambient and acidification conditions, and is influence to photosynthetic performance positively to many phytoplankton species. Generally, temperature also has a positive influences on membrane fluidity and the electron transport system (Falkowski and Raven, 2007), and increased temperature positively affects the potential efficiency of PSII photochemistry within the optimized temperature range (Lassen et al., 2010). Temperature also has an influence on the regulation of CCM capacity due to the solubility of $\mathrm{CO}_{2}$ and $\mathrm{O}_{2}$ (Baker and Oxborough, 2004; Giordano et al., 2005). A higher portion of $\mathrm{O}_{2}$ compared to $\mathrm{CO}_{2}$ could lead to the reduction of photosynthesis caused 
by competition between $\mathrm{O}_{2}$ and $\mathrm{CO}_{2}$ by RuBisCO, and enhanced photosynthesis could be induced by the high solubility of $\mathrm{CO}_{2}$ and low solubility of $\mathrm{O}_{2}$ in a warming ocean (Krause-Jensen et al., 1996). Therefore, we expect the decreasing PSII efficiency under acidification to be offset by the increasing temperature with the recovery of PSII efficiency.

Phytoplankton taxonomic groups and the succession of phytoplankton species could influence these physiological changes. A specific taxonomic group could be enhanced or inhibited by future climate conditions. In a North Atlantic study (shipboard continuous culture incubation system; Ecostat), the total $\mathrm{Chl} a$ under greenhouse treatment was higher than in ambient condition, and the dominant taxonomic group changed (Feng et al., 2009). In our mesocosm study, diatoms were the dominant taxonomic group during the overall experimental periods, and dinoflagellates increased somewhat in the post-bloom period (see Fig. S-3). More specifically, Skeletonema costatum, Chaetoceros spp., and Eucampia zodiacus were the dominant species within the diatom group, and the eight dominant species comprised more than $90 \%$ of the diatom abundance (Kim et al., 2010). Also, Akashiwo sanguinea, Nematodinium armatum, and Prorocentrum dentatum were the dominant species among dinoflagellates, and the six dominant species were comprised over $90 \%$ of the abundance of dinoflagellates (unpublished data). Some species benefited in terms of energetic balance for growth under acidified seawater from the previous laboratory and mesocosm studies (e.g., Skeletonema costatum: Kim et al., 2006; Synechococcus sp.: Fu et al., 2007; Thalassiosira pseudonana: Sobrino et al., 2008; Phaeodactylum tricornutum: Wu et al., 2010). In this mesocosm study, various species of diatoms and dinoflagellates responded differently to future climate conditions. For example, Skeletonema costatum, Chaetoceros spp. (positive to acidification condition), and Eucampia zodiacus (negative to acidification/greenhouse conditions) were largely affected by future climate conditions amongst the diatom group (Kim et al., 2010). In addition, Gyrodinoum spp. (positive to acidification/greenhouse conditions), Akashiwo sanguinea (negative to acidification/greenhouse conditions) and Nematodinium armatum (positive to greenhouse) responded differently in the dinoflagellate group (unpublished data). However, physiological data could not be partitioned into specie-specific Chl $a$ fluorescence and photosynthetic activities, because this study was investigated with community levels in response to future ocean conditions.

\subsection{Ecological implications}

Although the prediction of primary production has drawn considerable attention based on high $\mathrm{CO}_{2}$ oceans, the estimation of pelagic primary production under future climate conditions using a field mesocosm experiment has been rare. In a comparable previous study (PeECEIII), primary production did not dramatically change under a doubled $\mathrm{CO}_{2}$ concentra- tion (Egge et al., 2009). In addition, two previous shipboard experiments showed contrary results in primary production (Tortell et al., 2002; Gao et al., 2012). An equatorial Pacific phytoplankton community did not change, but the productivity of phytoplankton in the East/South China Sea decreased under high $\mathrm{CO}_{2}$ conditions. Daily and cumulative primary production results calculated from a short-term ${ }^{14} \mathrm{C}$ incorporation experiment (GCP) showed only minor effect of future climate conditions (Fig. 5a, b). However, we expect that primary production will be promoted with photosynthetic improvements under future ocean conditions based on physiological results. Indeed, the contribution of Chl $a$ to primary production ( $\mathrm{Chl} a$ normalized primary production) was increased under the greenhouse condition (Fig. 4c). Nevertheless, primary production of the phytoplankton community was unchanged, which could have resulted from potential environmental factors such as grazing activity (detailed below).

Biomass (Chl $a$ in this study) changes were directly linked to photosynthesis and primary production. In a previous study, biomass changes did not occur (Tortell et al., 2000), or small differences were observed (Riebesell et al., 2007; Feng et al., 2009) in the pelagic phytoplankton community, even when they were physiologically acclimated to high $\mathrm{CO}_{2}$ condition. In our data, biomass also did not increase in acidification and greenhouse conditions, despite the positive effects on the photo-physiology of phytoplankton under those conditions. Moreover, biomass growth was not observed under the greenhouse condition, even though photosynthesis was positively affected by temperature (Fig. 1). Surplus energy was theoretically generated by the downregulation of $\mathrm{CCMs}$ under high $\mathrm{CO}_{2}$ conditions, which might have further increased the phytoplankton biomass than with the energy in ambient condition. The optimal conditions for increases in biomass were the acidification and greenhouse conditions, but the biomass did not increase under these conditions over the experimental period. It seems that the biomass was not associated with physiological changes and production. This pattern represents the inconsistency between photosynthesis and primary production/biomass, which could be controlled by unexpected environmental factors. We suggest that one of the important factors is top-down regulation by grazers in mesocosm study, which will regulate phytoplankton blooms in the future ocean environment.

Grazing activity was significantly enhanced under acidification and greenhouse treatments after day 9 during the mesocosm experiment (Fig. S-4). The enhanced grazing rate was induced by heterotrophic dinoflagellate and microzooplankton under two sets of future conditions (Kim et al., 2010). Consequently, the abundance of grazers was increased, and positively affected by the two sets of future conditions, which also depressed the phytoplankton biomass blooms. Similarly to our study, Lewandowska and Sommer (2010) found remarkably lower phytoplankton biomass under warming conditions with enhanced top-down regulation induced by grazers such as zooplankton. Therefore, 
primary production and cell biomass of phytoplankton may be promoted in acidified coastal waters when top-down regulation is negligible.

\section{Summary}

Our mesocosm study offers information about photosynthesis, primary production and total biomass changes. To knowledge, this mesocosm study is the first to suggest photophysiological interpretation. The main objective of this study was to utilize photosynthetic performance as a means of evaluating physiological and ecological effects in the phytoplankton community under future climate conditions. The light utilization efficiency is accelerated for carbon assimilation through photosynthesis in a high $\mathrm{CO}_{2}$ world regardless of increases in temperature. The phytoplankton community could take advantage of inorganic carbon assimilation with optimized light utilization under future climate conditions, but these changes were not largely reflected in primary production and autotrophic phytoplankton biomass. Again, positive physiological changes do not have a major effect on ecological responses under acidification and greenhouse conditions, because of the enhanced abundance of grazers and their grazing pressure. Future studies should consider various environmental factors for controlling phytoplankton dynamics by investigating phytoplankton communities in future ocean environments.

\section{Supplementary material related to this article is available online at http://www.biogeosciences.net/10/ 7525/2013/bg-10-7525-2013-supplement.pdf.}

Acknowledgements. The authors would like to thank the comments of the two anonymous reviewers, D. A. Campbell, G. M. Hallegraeff, J.-P. Gattuso and responsible editor for their valuable comments. Also, the authors are grateful to E. J. Yang, M. Kim, H.-C. Kim, P.-G. Jang, M.C. Jang, and W.-J. Lee for field survey and technical support. This research was a part of the project titled "Long-term change of structure and function in marine ecosystems of Korea" funded by the Ministry of Oceans and Fisheries, Korea to KYK. Also, this work was partially supported by the National Research Foundation (NRF) of Korea Grant funded by the Korean Government (NRF-2011-0011940) to KYK.

Data sets are available online at http://mercury.chonnam.ac.kr/ ecoast/bbs/zboard.php?id=dataset

Edited by: C. Robinson

\section{References}

Baker, N. R. and Oxborough, K.: in: Chlorophyll fluorescence as a probe of photosynthetic productivity, edited by: Papageorgiou, G.C. and Govindjee, Chlorophyll $a$ fluorescence: a signature of photosynthesis, Springer, Dordrecht, 65-82 pp., 2004.

Beardall, J. and Raven, J. A.: The potential effects of global climate change on microalgal photosynthesis, growth and ecology, Phycologia, 43, 26-40, 2004.

Chen, X. and Gao, K.: Photosynthetic utilization of inorganic carbon and its regulation in the marine diatom Skeletonema costatum, Funct. Plant Biol., 31, 1027-1033, 2004.

Claquin, P., Probert, I., Lefebvre, S., and Veron, B.: Effects of temperature on photosynthetic parameters and TEP production in eight species of marine microalgae, Aquat. Microb. Ecol., 51, 1-11, 2008.

Egge, J. K., Thingstad, T. F., Larsen, A., Engel, A., Wohlers, J., Bellerby, R. G. J., and Riebesell, U.: Primary production during nutrient-induced blooms at elevated $\mathrm{CO}_{2}$ concentrations, Biogeosciences, 6, 877-885, doi:10.5194/bg-6-877-2009, 2009.

Falkowski, P. G. and Raven, R. A.: Aquatic Photosynthesis, 2nd edn., Princeton, NJ, Princeton University Press, 2007.

Feng, Y., Hare, C. E., Leblanc, K., Rose, J. M., Zhang, Y., DiTullio, G. R., Lee, P. A., Wilhelm, S. W., Rowe, J. M., Sun, J., Nemcek, N., Gueguen, C., Passow, U., Benner, I., Brown, C., and Hutchin, D. A.: Effects of increased $p \mathrm{CO}_{2}$ and temperature on the North Atlantic spring bloom. I. The phytoplankton community and biogeochemical response, Mar. Ecol. Prog. Ser., 388, 13-25, 2009.

Fu, F.-X., Warner, M. E., Zhang, Y., Feng, Y., and Hutchins, D. A.: Effects of increased temperature and $\mathrm{CO}_{2}$ on photosynthesis, growth, and elemental ratios in marine Synechococcus and Prochlorococcus (Cyanobacteria), J. Phycol., 43, 485-496, 2007.

Gao, K., Xu, J., Gao, K., Li, Y., Hutchins, D. A., Huang, B., Wang, L., Zheng, Y., Jin, P., Cai, X., Häder, D.-P., Li, W., Xu, K., Liu, N., and Riebesell, U.: Rising $\mathrm{CO}_{2}$ and increased light exposure synergistically reduce marine primary productivity, Nat. Clim. Chang., 2, 519-523, doi:10.1038/NCLIMATE1507, 2012.

Giordano, M., Beardall, J., and Raven, J. A.: $\mathrm{CO}_{2}$ concentrating mechanisms in algae: mechanisms, environmental modulation and evolution, Annu. Rev. Plant Biol., 56, 99-131, 2005.

Hare, C. E., Leblanc, K., DiTullio, G. R., Kudela, R. M., Zhang, Y., Lee, P. A., Riseman, S., and Huntchins, D. A.: Consequences of increased temperature and $\mathrm{CO}_{2}$ for phytoplankton community structure in the Bering Sea, Mar. Ecol. Prog. Ser., 352, 9-16, 2007.

Holm-Hansen, O. and Riemann, B.: Chlorophyll $a$ determination: improvements in methodology, Oikos, 30, 438-447, 1978.

Hopkinson, B. M., Xu, Y., Shi, D., McGinn, P. J., and Morel, F. M. M.: The effect of $\mathrm{CO}_{2}$ on the photosynthetic physiology of phytoplankton in the Gulf of Alaska, Limnol. Oceanogr., 55, 20112024, 2010.

Hopkinson, B. M., Dupont, C. L., Allen, A. E., and Morel, F. M. M.: Efficiency of the $\mathrm{CO}_{2}$-concentrating mechanism of diatoms, Proc. Nat. Acad. Sci., 108, 3830-3837, 2011.

IPCC Fourth Assessment Report: Climate Change: The Physical Science Basis; Intergovernmental Panel on Climatic Change; edited by: Solomon, S., Qin, S., Manning, M., Chen, Z., Marquis, M., Averyt, K. B., Tignor, M., and Miller, H. L., Cambridge University Press, New York, 2007. 
Kim, J.-H., Kang, E. J., Park, M.-G., Lee, B. G., and Kim, K. Y.: Effects of temperature and irradiance on photosynthesis and growth of a green-tide-forming species (Ulva linza) in the Yellow Sea, J. Appl. Phycol., 23, 421-432, 2011a.

Kim, J.-M, Lee, K., Shin, K., Kang, J. H., Lee, H. W., Kim, M., Jang, P. G., and Jang, M. C.: The effect of seawater $\mathrm{CO}_{2}$ concentration on growth of a natural phytoplankton assemblage in a controlled mesocosm experiment, Limnol. Oceanogr., 51, 1629_ 1636, 2006.

Kim, J.-M., Lee, K., Yang, E. J., Shin, K., Noh, J. H., Park, K. T., Hyun, B., Jeong, H.-J., Kim, J-.H., Kim, K. Y., Kim, M., Kim, H.C., Jang, P. G., and Jang, M. C.: Enhanced production of oceanic dimethylsulfide resulting from $\mathrm{CO}_{2}$-induced grazing activity in a high $\mathrm{CO}_{2}$ world, Environ. Sci. Technol., 44, 8140-8143, 2010.

Kim, J.-M., Lee, K., Shin, K., Yang, E. J., Engel, A., Karl, D. M., and Kim, H.-C.: Shift in biogenic carbon from particulate to dissolved forms under high carbon dioxide and warm ocean conditions, Geophys. Res. Lett., 38, L08612, doi:10.1029/2011GL047346, 2011b.

Kim, J.-M., Shin, K., Lee, K., and Park, B.-K.: In situ ecosystembased carbon dioxide perturbation experiments: Design and performance evaluation of a mesocosm facility, Limnol. Oceanogr. Methods, 6, 208-217, 2008.

Kim, K., Kim, K. Y., Kim, J.-H., Kang, E. J., Jeong, H. J., and Lee, K.: Synergistic effects of elevated carbon dioxide and sodium hypochlorite on survival and impairment of three phytoplankton species, Algae, 28, 173-183, 2013.

Krause-Jensen, D., McGlathery, K., Rysgaard, S., and Christensen, P. B.: Production within dense mats of the filamentous macroalga Chaetomorpha linum in relation to light and nutrient availability, Mar. Ecol. Prog. Ser., 134, 207-216, 1996.

Lassen, M. K., Nielsen, K. D., Richardson, K., Garde, K., and Schlüter, L.: The effects of temperature increases on a temperate phytoplankton community - A mesocosm climate change scenario, J. Exp. Mar. Biol. Ecol., 383, 79-88, 2010.

Lewandowska, A. and Sommer, U.: Climate change and the spring bloom: a mesocosm study on the influence of light and temperature on phytoplankton and mesozooplankton, Mar. Ecol. Prog. Ser., 405, 101-111, 2010.

MacKenzie, T. D. B., Burns, R. A., and Campbell, D. A.: Carbon status constrains light acclimation in the cyanobacterium Synechococcus elongates, Plant Physiol., 136, 3301-3312, 2004.

MacKenzie, T. D. B., Johnson, J. M., and Campbell, D. A.: Dynamic of fluxes through photosynthetic complexes in response to changing light and inorganic carbon acclimation in Synechococcus elongates, Photosynth. Res., 85, 341-57, 2005.

McCarthy, A., Rogers, S. P., Duffy, S. J., and Campbell, D. A.: Elevated carbon dioxide differentially alters the photophysiology of Thalassiosira pseudonana (Bacillariophyceae) and Emiliania huxleyi (Haptophyta), J. Phycol., 48, 635-646. 2012.

Platt, T., Gallegos, C., and Harrison, W. G.: Photoinhibition of photosynthesis in natural assemblage of marine phytoplankton, J. Mar. Res., 28, 687-701, 1980.

Ralph, P. J. and Gademann, R.: Rapid light curves: a powerful tool to assess photosynthetic activity, Aquat. Bot., 82, 222-237, 2005.
Raven, J. A.: Physiology of inorganic C acquisition and implications for resource use efficiency by marine phytoplankton: Relation to increased $\mathrm{CO}_{2}$ and temperature, Plant Cell Environ., 14, 779-794, 1991.

Raven, J. A.: Inorganic carbon acquisitions by eukaryotic algae: four current questions, Photosynth. Res., 106, 123-134, 2010.

Riebesell, U.: Effects of $\mathrm{CO}_{2}$ enrichment on marine phytoplankton, J. Oceanogr., 60, 719-729, 2004.

Riebesell, U., Bellerby, R. G. J., Grossart, H.-P., and Thingstad, F.: Mesocosm $\mathrm{CO}_{2}$ perturbation studies: from organism to community level, Biogeosciences, 5, 1157-1164, doi:10.5194/bg-51157-2008, 2008.

Riebesell, U., Schulz, K. G., Bellerby, R. G. J., Botros, M., Fritsche, P., Meyerhöfer, M., Neill, C., Nondal, G., Oschlies, A., Wohlers, J., and Zöllner, E.: Enhanced biological carbon consumption in a high $\mathrm{CO}_{2}$ ocean, Nature, 450, 545-548, 2007.

Rose, J. M., Feng, Y., Gobler, C. J., Gutierrez, R., Hare, C. E., Leblanc, K., and Hutchins, D. A.: Effects of increased $\mathrm{pCO}_{2}$ and temperature on the North Atlantic spring bloom. II. Microzooplankton abundance and grazing, Mar. Ecol. Prog. Ser., 388, 2740, 2009.

Rost, B., Riebesell, U., Burkhardt, S., and Sültemeyer, D.: Carbon acquisition of bloom-forming marine phytoplankton, Limnol. Ocenogr., 48, 55-67, 2003.

Schippers, P., Lürling, M., and Scheffer, M.: Increase of atmospheric $\mathrm{CO}_{2}$ promotes phytoplankton productivity, Ecol. Lett. 7, 446-451, 2004.

Sobrino, C., Ward, M. S., and Neale, P. J.: Acclimation to elevated carbon dioxide and ultraviolet radiation in the diatom Thalassiosira pseudonana: Effects on growth, photosynthesis, and spectral sensitivity of photoinhibition, Limnol. Oceanogr., 53, 494-505, 2008.

Sommer, U. and Lengfellner, K.: Climate change and the timing, magnitude, and composition of the phytoplankton spring bloom, Glob. Change Biol., 14, 1199-1208, 2008.

Sommer, U. and Lewandowska, A.: Climate change and the phytoplankton spring bloom: warming and overwintering zooplankton have similar effects on phytoplankton, Glob. Change Biol., 17, 154-162, 2010.

Strickland, J. D. and Parson, T. R.: A practical handbook of seawater analysis, 2nd edn., Bull. Fish Res., Board Can., 167, 310 pp., 1972

Tortell, P. D., DiTullio, G. R., Sigman, D. M., and Morel, F. M. M.: $\mathrm{CO}_{2}$ effects on taxonomic composition and nutrient utilization in an Equatorial Pacific phytoplankton assemblage, Mar. Ecol. Prog. Ser., 235, 37-43, 2002.

Tortell, P. D., Rau, G. H., and Morel, F. M. M.: Inorganic carbon acquisition in coastal Pacific phytoplankton communities, Limnol. Oceanogr., 45, 1485-1500, 2000.

Wu, Y., Gao, K., and Riebesell, U.: $\mathrm{CO}_{2}$-induced seawater acidification affects physiological performance of the marine diatom Phaeodactylum tricornutum, Biogeosciences, 7, 29152923, doi:10.5194/bg-7-2915-2010, 2010.

Ye, Z.-P.: Nonlinear optical absorption of photosynthetic pigment molecules in leaves, Photosynth. Res., 112, 31-37, 2012. 